\title{
Orthodontic treatment in adults: Restoring smile esthetics
}

\author{
Leopoldino Capelozza Filho1, Maria Fernanda Barros Aranha², Terumi Okada Ozawa ${ }^{3}$, Arlete de Oliveira Cavassan ${ }^{4}$
}

\begin{abstract}
Introduction: The search for orthodontic treatment by adult patients is increasing. This demand may be explained by many reasons, but the most important was the change in the concept of normality, allowing the selection of simpler and more conservative and consistent therapeutic objectives. This conceptual evolution, combined with the technological advances allowed an improvement in orthodontic management, making it more effective, fast and comfortable. The promotion of awareness of the society on the advantages of this treatment and the increase in esthetic demands, with an increasingly longer and active social, affective and professional life, creates a context in which the need for Orthodontics is absolutely established for the adult individuals. Objective: The objective of this article is to report the nuances in diagnosis and orthodontic treatment of an adult patient, in a different perspective. Within this approach, the objective is to recover the shape, i.e. to establish occlusal conditions that would probably be present if the patient had been assisted at the proper time, namely during growth and tooth irruption.
\end{abstract}

Keywords: Orthodontics. Smile esthetics.

Introdução: a procura de tratamento ortodôntico por pacientes adultos é cada vez maior. Essa demanda pode ser justificada por vários fatores, mas o mais relevante foi a mudança do conceito de normal, permitindo a opção por metas terapêuticas mais conservadoras, simples e consistentes. Essa evolução conceitual, mais os avanços tecnológicos, permitiram melhora no manejo ortodôntico, tornando-o mais efetivo, rápido e confortável. A conscientização, por parte da sociedade, das vantagens desse tratamento e o aumento da exigência estética entre os adultos, com uma vida social, afetiva e profissional cada vez mais longa e ativa, cria um contexto onde fica absolutamente estabelecida a necessidade de uma Ortodontia para os indivíduos adultos. Objetivo: o objetivo desse artigo foi relatar as nuances de diagnóstico e tratamento ortodôntico em um paciente adulto, dentro de uma perspectiva reformadora. Nessa abordagem, o objetivo é o resgate da forma, ou seja, estabelecer condições oclusais que, provavelmente, estariam presentes se o paciente tivesse sido assistido em épocas adequadas, na fase de crescimento e erupção dentária.

Palavras-chave: Ortodontia. Estética do sorriso.

\section{INTRODUCTION}

The prevalence of malocclusion is certainly greater in adults. It may be stated that malocclusion is directly proportional to age, and that its characteristics reflect the good or poor care of all teeth, since the early deciduous dentition. In Brazil, we have the first generation with a significant number of individuals that reach adulthood and begin to age

» Patients displayed in this article previously approved the use of their facial and intraoral photographs.

${ }^{1}$ Coordinator of the Specialization Course in Orthodontics at PROFIS and University of Sagrado Coração USC.

${ }^{2}$ Post-Graduation student in Orthodontics, PROFIS.

${ }^{3}$ Orthodontist and Director of the Dental Division at HRAC-USP.

${ }^{4} \mathrm{MSc}$ in Orthodontics, FOB-USP. Orthodontist at HRAC-USP. with all or nearly all teeth in the mouth. Therefore, similar to socially developed countries, they start to present malocclusion characterized by tooth crowding. Proffit et $\mathrm{al}^{8}$ conducted a study based on an epidemiological survey of NIH to determine the prevalence of malocclusion and orthodontic treatment need in the American population, which revealed that, in general, $70 \%$ of adult patients have

How to cite this article: Capelozza Filho L, Aranha MFB, Ozawa TO, Cavassan AO. Orthodontic treatment in adults: Restoring smile esthetics. Dental Press J Orthod. 2012 Sept-Oct;17(5):53-63.

Submitted: July 30, 2009 - Revised and accepted: Juny 26, 2012.

" The authors report no commercial, proprietary or financial interest in the products or companies described in this article.

Contact address: Leopoldino Capelozza Filho

Rua Dr. Servio Tulio Carrijo Coube, 2-70 Jd. Infante D. Henrique - Bauru/SP - Brazil Zip code: 17.012-632 - E-mail: lcapelozza@yahoo.com.br 
malocclusions with an objective treatment need, a value that has been considered a consensus in the literature. Individuals with tooth crowding equal to or smaller than $3.5 \mathrm{~mm}$ and alterations in molar relationship that did not cause significant changes in esthetics and occlusion were considered as normal. That is to say, these individuals would not have an objective treatment need, yet this does not rule out the subjective need which is increasingly significant in the Western population, including our country.

The number of adult patients searching for orthodontic treatment has been increasingly greater. American data from the early $1990 \mathrm{~s}^{7}$ demonstrate that the percentage of adult patients in specialized orthodontic clinics was $30 \%$ and this percentage was expected to increase until the end of the decade. This was clearly confirmed.

This increased demand is a consequence of four factors: The first is the use of preventive measures in Dentistry, allowing the patient to reach adulthood with a greater number of teeth in the mouth; the second is the increased esthetic demand of society; the third comprises greater access to information by the population, which promotes the awareness among adults that orthodontic treatment is an accessible resource to enhance the appearance of teeth and even the face; and the fourth factor is the modernization of more esthetic and comfortable orthodontic appliances. ${ }^{2}$ However, the most important factor was the change in the concept of normality for adults. This changed the therapeutic goals, contributing especially to reduce the treatment time, which is the greatest factor of resistance to treatment among adults.

Adult orthodontic patients may or not differ from adolescent orthodontic patients, depending on the severity of malocclusion, quantity of restorations, previous trauma or abrasion of teeth, susceptibility to periodontal disease, temporomandibular disorders and history of dental caries. One of the main advantages in the treatment of adults is the several years of dental history to be considered, allowing a better understanding on the meaning of occlusal alterations observed and their potential as a problem. ${ }^{6}$

The orthodontic treatment in growing individuals nearly always aim to achieve the six keys to normal occlusion of Andrews ${ }^{1}$ and the best esthetics possible. In adult patients, this goal should not be an obligation.
Many adults lived many years with a malocclusion without recognizing these deviations from normality as a problem. The patient may simply need to have the teeth aligned, spaces opened for restorations or replace missing teeth, dental arches leveled to improve the overbite, erupted teeth to solve periodontal problems or upright teeth for future restorations. In these cases, a dental Angle Class I relationship or other parameters considered as ideal may not be necessary. This is especially true if the patient does not have temporomandibular disorders, periodontal problems or tooth abrasions ${ }^{6}$ or, in other words, has a functional occlusion.

Within this concept applied realistically, ${ }^{2}$ this paper introduces one of the treatment modalities indicated for adults. Restoring the occlusion, respecting the individual characteristics of normality and assigning the dental relationships the conditions they would probably have if the eruption and growth circumstances had allowed. We call this a shape recovery, or the attempt to restore to the patient the occlusion he or she would have if ideal conditions had been allowed. Therefore, this reference or model is absolutely individual and allows treatment with well-defined goals, usually viable, conservative, faster and especially potentially stable because of the little speculation. This concept is specifically applied to the treatment of the lower dental arch in the presented case. In the upper arch, extractions were necessary, justified to attend the patient's expectations, but this did increase case complexity, interfering, mostly, with treatment time. Anyway, using the restored lower arch as a parameter to establish occlusal relations, probably the essence of what is being proposed for the treatment with shape recovery, was preserved.

\section{CASE REPORT \\ Diagnosis}

Adult male patient aged 36 years and 6 months, Caucasian, attended the specialization orthodontic clinic at PROFIS - HRAC-USP/Bauru with chief complaint about the esthetics of occlusion.

The initial consultation comprised clinical evaluation of the face and intraoral clinical examination. The subjective facial analysis ${ }^{3}$ in frontal view revealed proportion between the upper, medium 
and lower facial thirds, symmetry, good zygomatic projection and passive lip sealing. The profile analysis evidenced open nasolabial angle, acceptable mentolabial sulcus and Q-P line, confirming the acceptable diagnosis of a Pattern I face.

Parameters as passive lip sealing and lip relationship with the nose and chin are directly related to esthetics and are fundamental in the diagnosis of patients that will be indicated for compensatory and/or corrective treatment. ${ }^{3}$ The patient presented an acceptable face, yet impaired in the profile analysis by the moderate retrusion of the upper lip (open nasolabial angle). The use of a moustache masks the clinical visualization of this detail (Fig 1).

The intraoral evaluation demonstrated Class II relationship (Fig 2), probable agenesis of tooth \#12, considering that the patient reported no history of extraction, tooth \#22 presented shape alteration (microdontia), early loss of teeth \#36 and 46 and missing teeth \#16 and 48. The maxillary midline deviation of $3 \mathrm{~mm}$ to the right side, one of the patient's chief complaints, was noticeable, because the patient presented the three alterations that the maxillary midline should not have: Deviation of dental
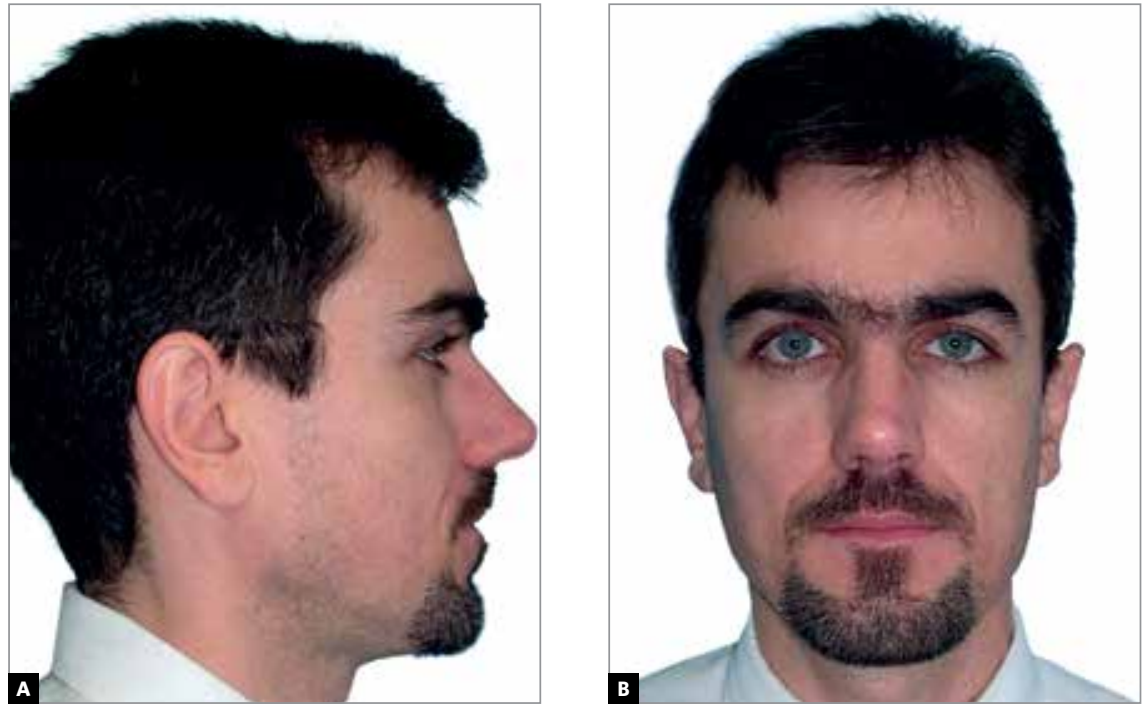

Figure 1 - Initial facial photographs reveal a dolichofacial Pattern I patient with acceptable face.
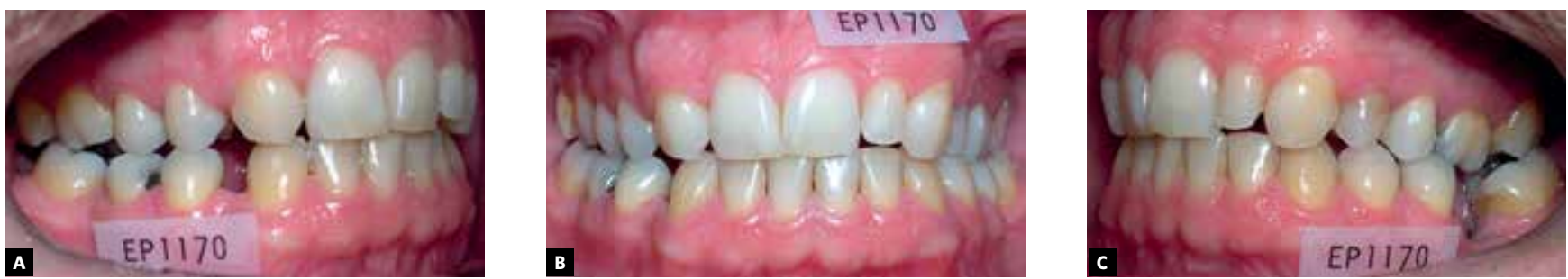

Figure 2 - Initial intraoral photographs. Observe the Class II sagittal relationship, maxillary midline deviation and flattening of the maxillary arch on the right side.

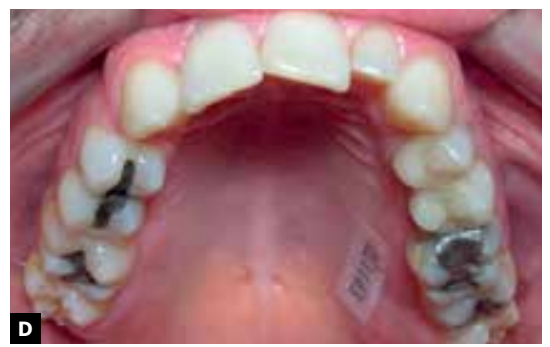

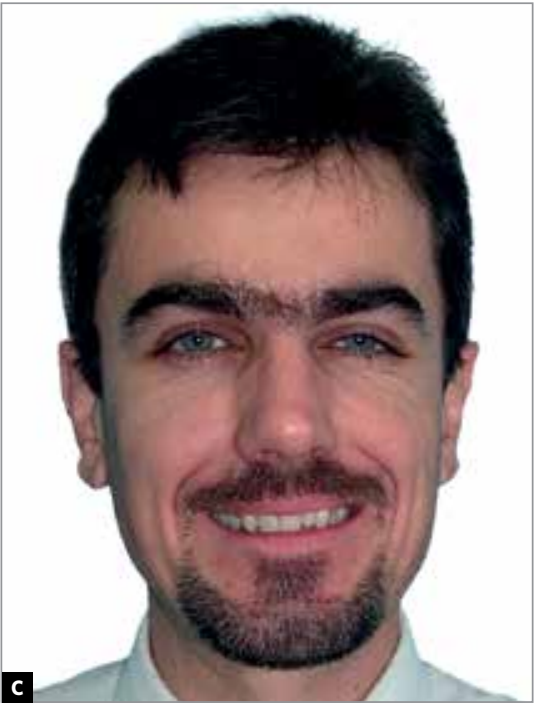

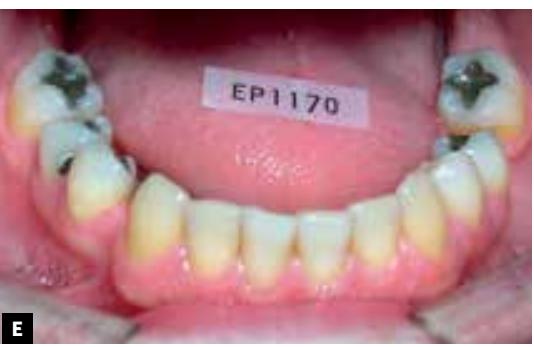


midline in relation to the facial midline, loss of perpendicular line between the mesial interincisal surfaces of central incisors and the occlusal plane, and flattening of the arch at the side of deviation. Also, the maxillary arch was atresic and the mandibular arch was compensated (Fig 2).

After consultation, the patient was referred for orthodontic records to complement the initial examinations and allow the diagnosis, prognosis and treatment planning.

Analysis of these records confirmed all clinical findings of initial evaluation. Morphological analysis of the lateral cephalogram ${ }^{3}$ exhibited characteristics of normality for Pattern I, dolichofacial. The aspect was harmonious, with adequate soft tissue profile, passive lip sealing, proportion of medium and lower facial thirds, proportion of components of the lower third, and nasolabial angle with moderate opening, which impaired the lack of convexity. Skeletal analysis evidenced horizontal planes slightly divergent from each other. The maxillomandibular relationship was good both in vertical and anteroposterior directions, the overjet and overbite were borderline due to the missing maxillary teeth, interfering with the position of maxillary incisors, which were retroclined in the basal bone. The roots of mandibular incisors were closer to the lingual than to the buccal cortical plate, sufficient to adequately support these teeth. The root apices of maxillary molars were at a normal distance from the palatal plane, an important data to establish the normality of a dolichofacial individual ${ }^{3}$ (Fig 3).

Evaluation of the panoramic radiograph confirmed agenesis of tooth \#12 and absence of teeth \#16, 36, 38, 46 and 48. The maxillary left first premolar had endodontic treatment and vertical bone loss was observed on the mesial aspect of tooth \#37 (Fig 4).

Analysis of dental casts confirmed the bilateral Class II molar relationship (Fig 5) and the occlusal analysis evidenced the relative retrusion of the maxillary arch, with flattening on the right side (Fig 6A).

The prognosis was defined as good for corrective orthodontic treatment (COT), ${ }^{3}$ aiming to restore the dental arch shape.

\section{Treatment planning}

Considering that the patient's complaint was exclusively dental esthetics, treatment was proposed with the primary goal to achieve better smile esthetics, i.e. a multidisciplinary treatment. ${ }^{9}$ Spear et al ${ }^{9}$ described that, in treatment planning, the sequence of procedures aiming at maintaining the biological structure and for esthetic purposes is fundamental for the final esthetic outcome.

The planning comprised extraction of tooth \#24 to correct the maxillary midline with the face, allowing compensation of two missing teeth on the right side: Agenesis of tooth \#12 and early extraction of tooth \#16. This procedure would allow repositioning the teeth that migrated due to the spaces available.

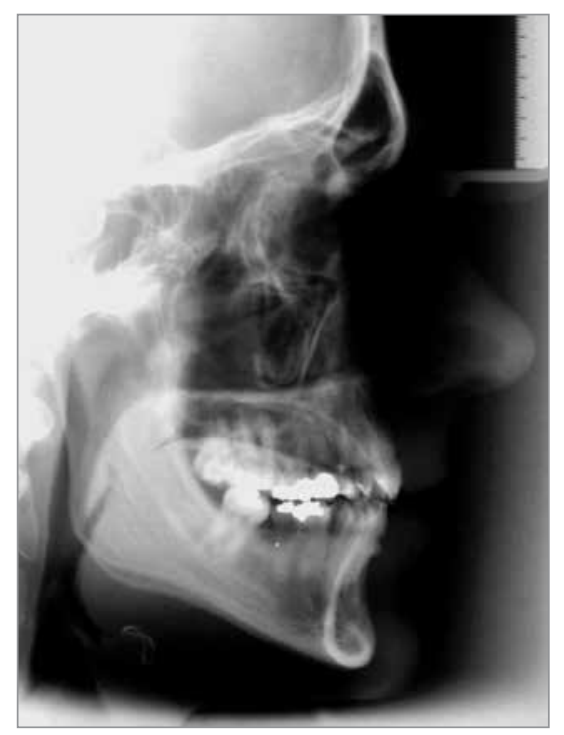

Figure 3 - Lateral cephalogram.

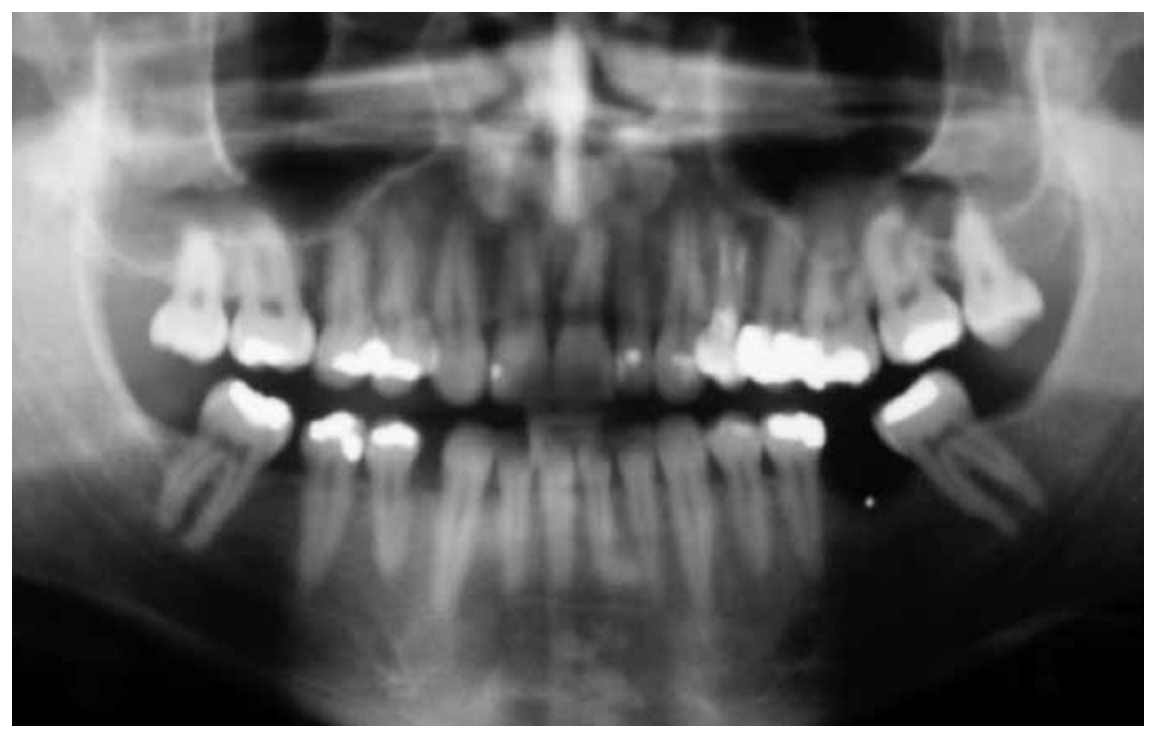

Figure 4 - Panoramic radiograph. Observe the absence of teeth \#12, 16, 36, 38, 46 and 48. 

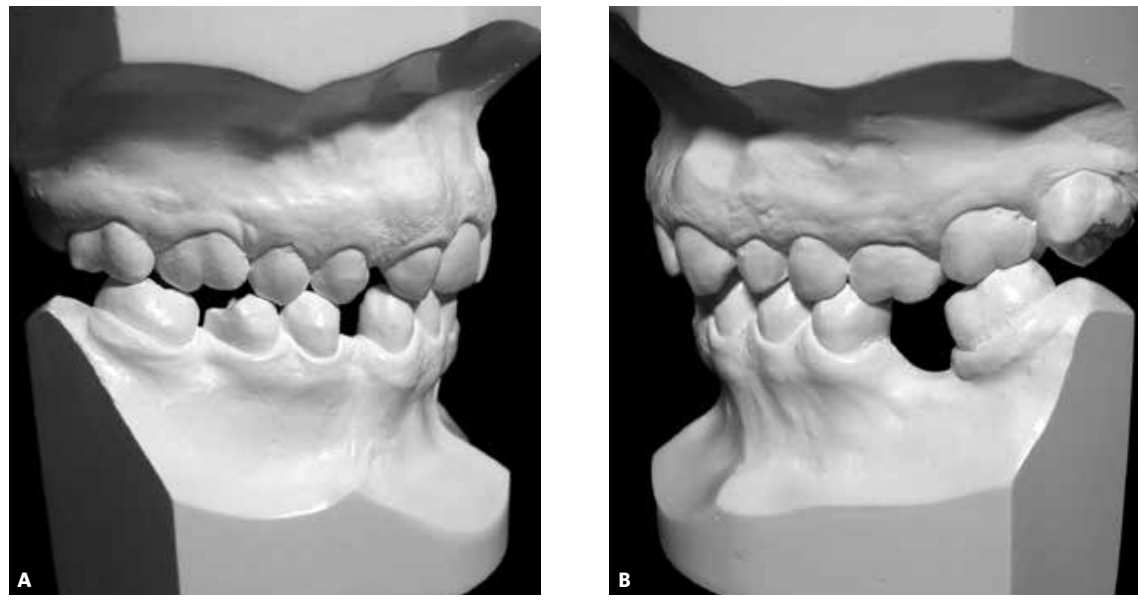

Figure 5 - Photographs of initial dental casts evidencing the bilateral Class II sagittal relationship.

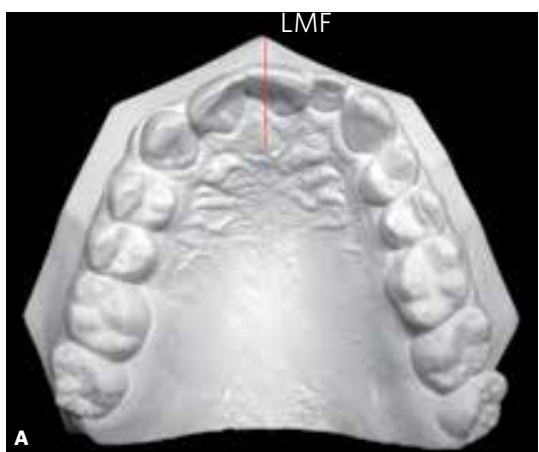

Figure 6 - Occlusal photographs of maxillary and mandibular dental casts. A) Observe the maxillary midline deviation to the right side due to agenesis of tooth \#12, causing flattening of the maxillary arch on the right side. B) In the mandibular arch, observe the spaces left by missing teeth and rotation of tooth \#45.

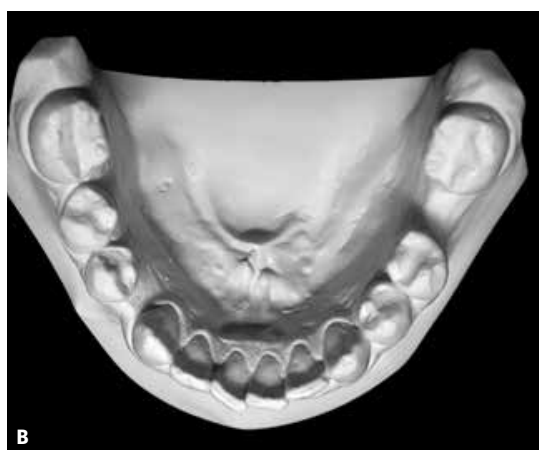

Figure 7 - Choice of the Individual Anatomic Objective Diagram.
Teeth on the left side, that invaded the midline when migrating to the right side, would be returned to their original positions, and teeth on the right side, that migrated distally, might be repositioned according to the midline, allowing space to replace tooth \#12 using an implant. In other words, the maxillary arch shape would be recovered allowing conditions for a better symmetry. The potential stability of this approach is reinforced by the little speculation, since the approach adopted comprised deconstruction of the malocclusion, considering as the base for creation the agenesis of tooth \#12, early extraction of tooth \#16 and related disorders. From this perspective, planning defined the achievement of space to replace tooth \#12 using an implant and reshaping the tooth \#22.
In the mandibular arch, the goal was to maintain space between tooth \#35 and 37 for implant placement at the region of tooth \#36 and achievement of space between teeth \#44 and 45 for placement of an implant with a mandibular third premolar between them. The advantage of this procedure, namely the achievement of space between two teeth for implant placement in this created space, is the new bone between them to provide an area with better tissue quality to receive an implant (Fig 8). The planning for implant positioning was evaluated and approved by the implantologist after planning and before treatment.

Selection of the ideal diagram for the patient is fundamental at this stage, because the treatment goals should be considered and incorporated in 
the dental arch shape. This means that the leveling archwires will include the goal manifested in treatment planning 5 .

The shape of maxillary and mandibular leveling archwires followed the individual objective anatomic diagram (IOAD) C4A6. ${ }^{5}$ Selection of the diagram in young patients or submitted to conventional orthodontic treatment is always based on the mandibular arch. This is not a rule for the treatment of adult patients, in which specific and localized goals may be defined. In this case, the diagram is selected according to the dental arch or arch segment selected as reference. In the present case the mandibular arch could be taken as reference because the treatment had very conventional goals, without the objective to introduce significant changes in the contour of this dental arch. The anterior curvature should adjust to the original intercanine distance if adequate, otherwise it should be defined by the established therapeutic goal. In this case the intercanine distance was followed, as well as the original position of mandibular incisors, which was similar to the desired (to avoid protrusion). The posterior opening of the dental arch should adjust to the Wala ridge or the desirable intermolar width at treatment completion. ${ }^{5}$ In this case, we intended to maintain the intermolar distance and thus the selected diagram should be passive in the tubes of mandibular molars. In summary, the therapeutic goal was to maintain the mandibular arch width (Fig 7), characterizing a situation in which the treatment objective is superimposed to the anatomical characteristics of normality and determines the parameters of choice for the posterior opening of the diagram, which may be coincident or not with the diagram that would be determined by the other perspective. As always, when this routine is followed, the maxillary arch should have the same shape, magnified following the classical orientation for the use of straight wire brackets. Therefore, the maxillary arch will always be coordinated with the mandibular arch and will be handled on the selected diagram throughout the leveling stage. Changes may be introduced, and as in the present case they are always introduced when the diagram arch shape is unable to introduce changes as desired. Therefore, only when absolutely necessary and with minimum speculation on treatment, as previously described, it aims to restore the arch shape and occlusion that the patient should have.

In summary, the objective of the planed therapeutic approach (Fig 8) was to recover the shape and space in the maxillary and mandibular arches, restoring the occlusal stability and providing better esthetic quality to the maxillary anterior region.

Initially, a transpalatal bar (TPB) was placed as anchorage unit. Bonding of maxillary teeth was made using Capelozza brackets prescription $\mathrm{I},{ }^{4}$ with individualized angulation of $0^{\circ}$ on tooth \#11, aiming to avoid distal angulation of the root, maintaining the area for implant placement to replace the tooth \#12. Extraction of tooth \#24 was requested followed by maxillary leveling with initial retraction of tooth \#23 from the first leveling archwire. Retraction of this tooth was very slow because the patient exhibited alveolitis after extraction of tooth \#24, with consequent delay in healing of the area (Fig 9).

The mandibular appliance was placed when the maxillary arch presented a more adequate shape. Banding of teeth \#37 and 47 and direct bonding of the other mandibular teeth with Capelozza brackets prescription $\mathrm{I}^{4}$ was made, with onset of mandibular leveling with 0.016-in nickel titanium archwire. Space was gained between teeth \#44 and 45 using an active open coil maintained between these teeth during leveling. This movement provides new bone in the area that will receive the implant.

The treatment was continued with the planned intra-arch mechanics for the maxillary and mandibular arches, with follow-up at every three weeks, with active intervention in one dental arch and only revision in the other, which allowed adequate control of occurrence and actual activation of the appliance at longer intervals. This is important in adult patients, whose remodeling and consequent treatment response are supposedly slower.

The maxillary leveling was continued using an open coil between teeth \#11 and 13, distalization of tooth \#23 and enhancement of correction of the maxillary midline deviation using a midline bend in the 0.018-in archwire. This bend is a transgression to the arch shape established by the previously selected diagram, and is adopted because the conventional shape of the leveling archwire is not transferred to the dental 
Figure 8 - Schemes graphically demonstrating the original problem, proposal of movement and expected tooth positioning at treatment completion.

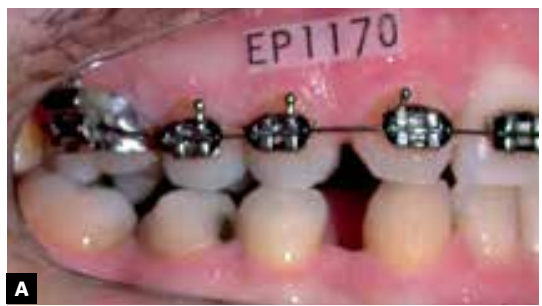

Figure 9 - After placement of TPB tooth \#24 was indicated for extraction, after which selective bracket bonding was performed (tooth \#11 with $0^{\circ}$ of angulation). Maxillary leveling was initiated with nickel titanium 0.016-in archwire and initial retraction of tooth \#23 with an active lace back.
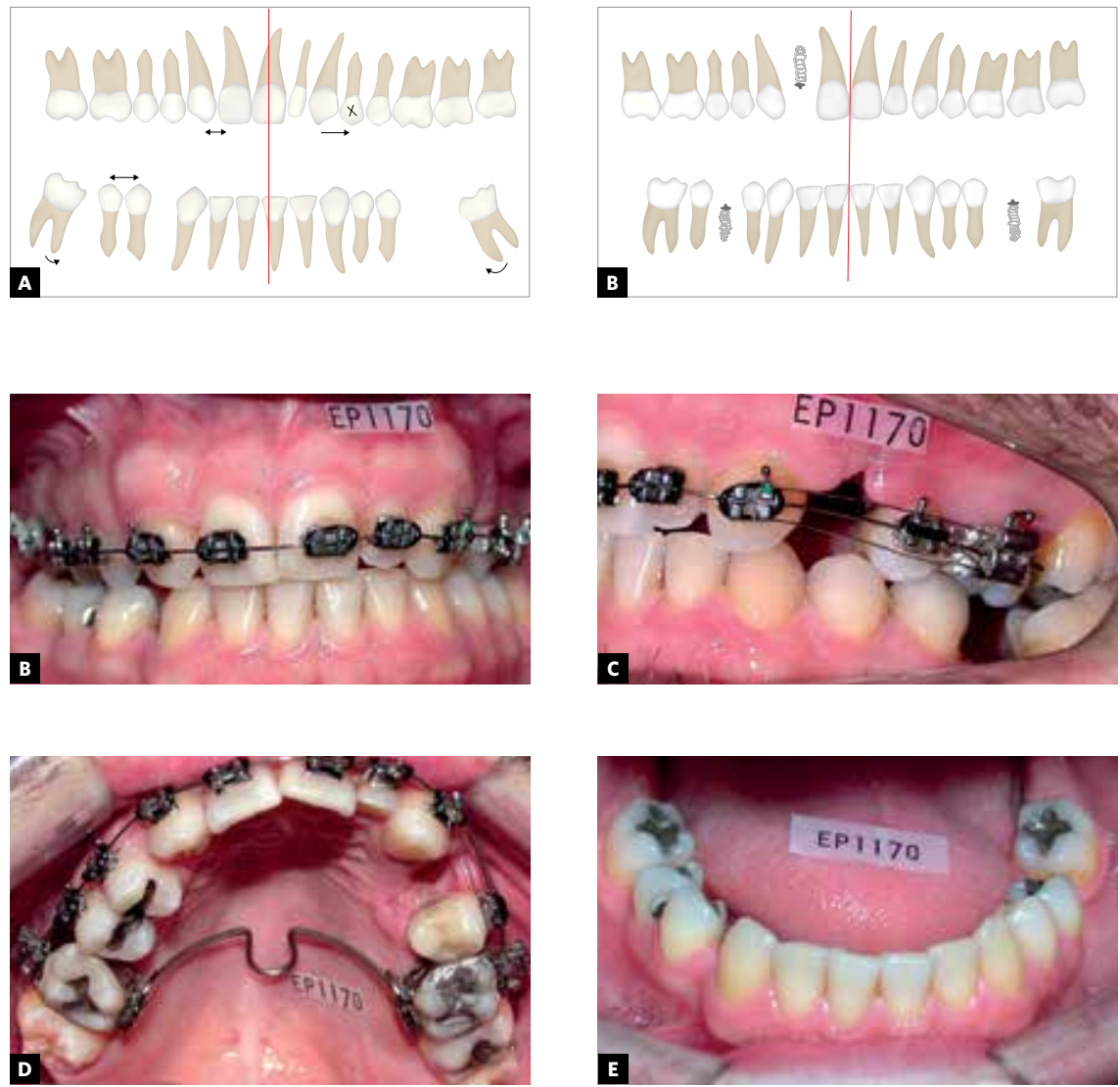
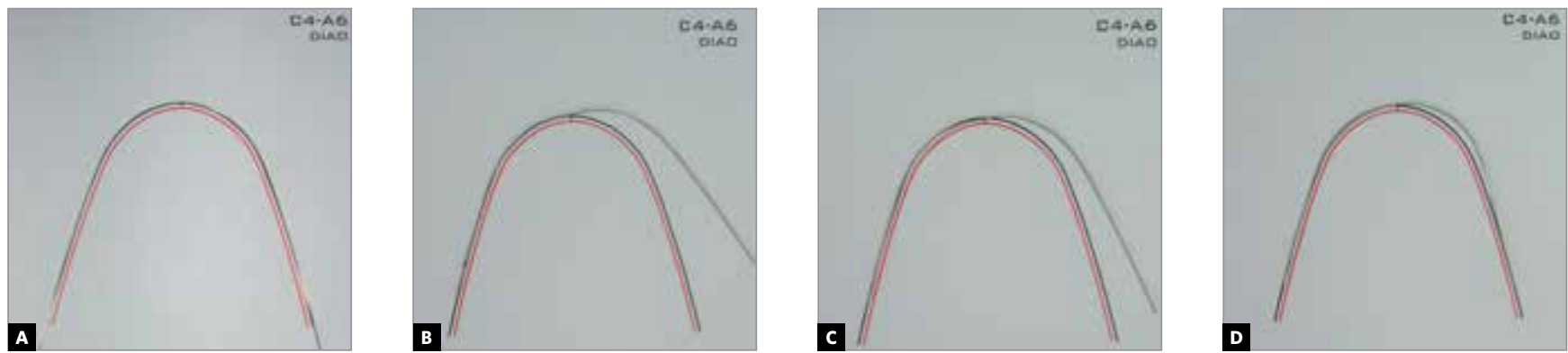

Figure 10 - Sequence of fabrication of midline bend in the maxillary 0.018-in stainless steel archwire.

arch. This bend was made in the midline of the maxillary leveling archwire (0.018-in round stainless steel), determined from the facial midline, to enlarge the flattened arch side (right side) and aid the correction of one defect that emphasizes the dental midline deviation. The leveling archwire is initially contoured on the diagram; an omega is then introduced close to the molar tube on the correct side (in this case, mesial aspect of tooth \#26). The point corresponding to the facial midline is marked in the leveling archwire and the midline bend is made for transverse action (Fig 10B). The archwire portion that deviates from the diagram should involve only the teeth in which a protrusive effect is desired, namely the anterior teeth on the right side in the present case. This way, it is intended to cancel the transverse effect of the bend, allowing buccal movement of the target region, in this case the anterior teeth on the right side. The greatest distance of the archwire at the bend region to the diagram should be 3 $\mathrm{mm}$. This distance in the 0.018 -in round stainless steel archwire generates a force that has been clinically effective to produce movement, without negative biological response. In summary, with this contour and the omega tied to the molar tube on the opposite side, the archwire segment contained in the midline bend (segment outside the diagram) is compressed inside 

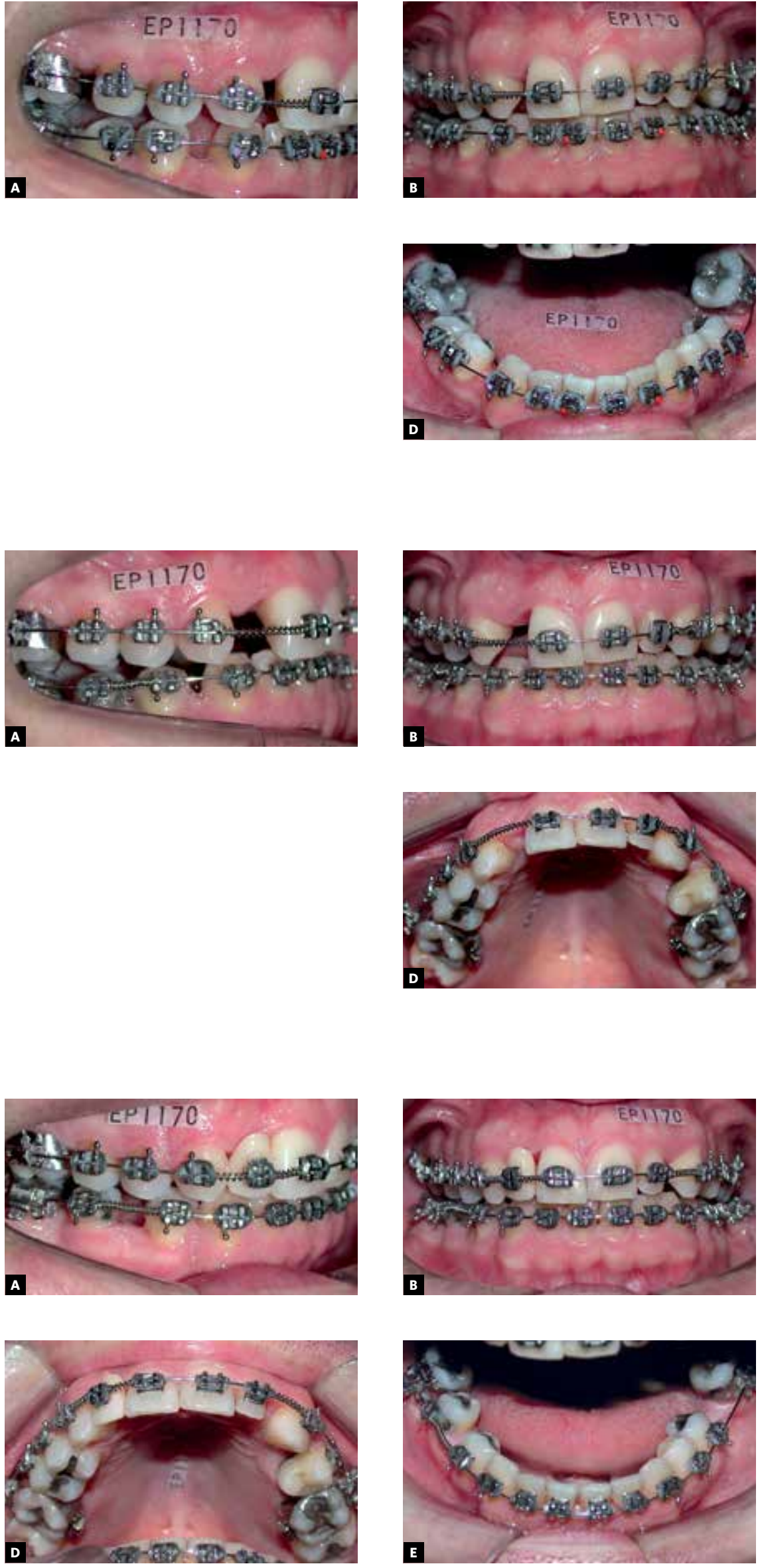
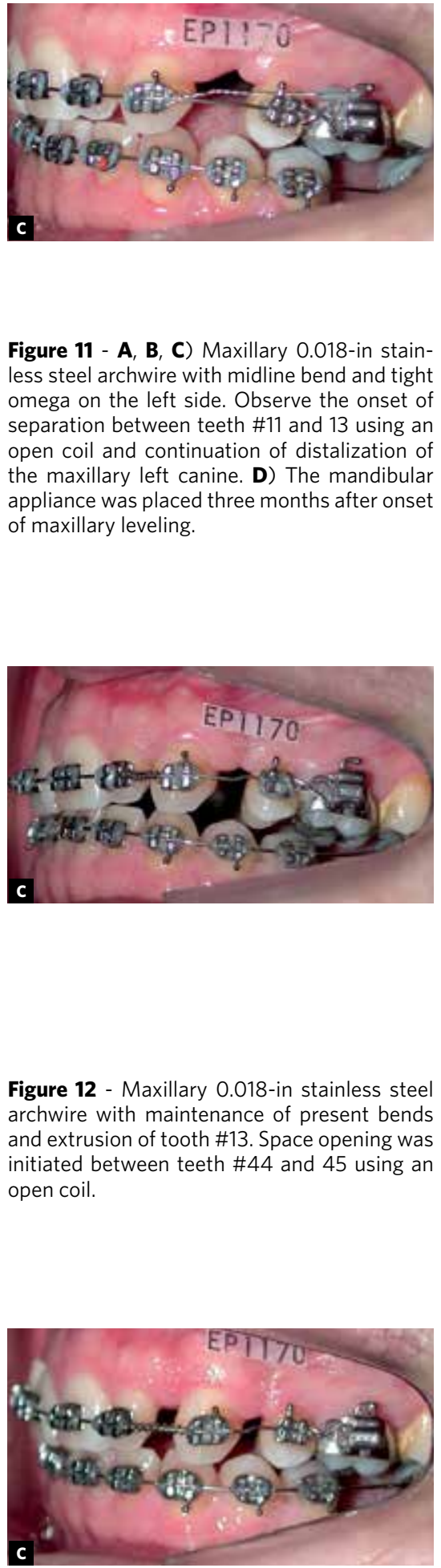

Figure 11 - A, B, C) Maxillary 0.018-in stainless steel archwire with midline bend and tight omega on the left side. Observe the onset of separation between teeth \#11 and 13 using an open coil and continuation of distalization of the maxillary left canine. D) The mandibular appliance was placed three months after onset of maxillary leveling.

Figure 12 - Maxillary 0.018-in stainless steel archwire with maintenance of present bends and extrusion of tooth \#13. Space opening was initiated between teeth \#44 and 45 using an open coil.

Figure 13 - Placement of a pontic tooth at the region of tooth \#12 to provide esthetics and placement of open coil between teeth \#22 and 23 to aid the distalization of tooth \#23. Observe the space created between teeth \#44 and 45 and enhanced configuration of the maxillary arch. 


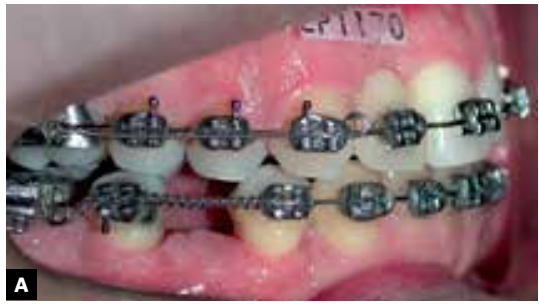

Figure 14 - Maxillary 0.018-in stainless steel archwire with the same bends as the previous and loop on the mesial aspect of canines for maxillary anterior retraction. The goal was to enhance the overjet. In the mandibular arch, leveling with 0.018-in stainless steel archwire was nearly completed and the space for an implant at the region between teeth \#44 and 45 was sufficient.
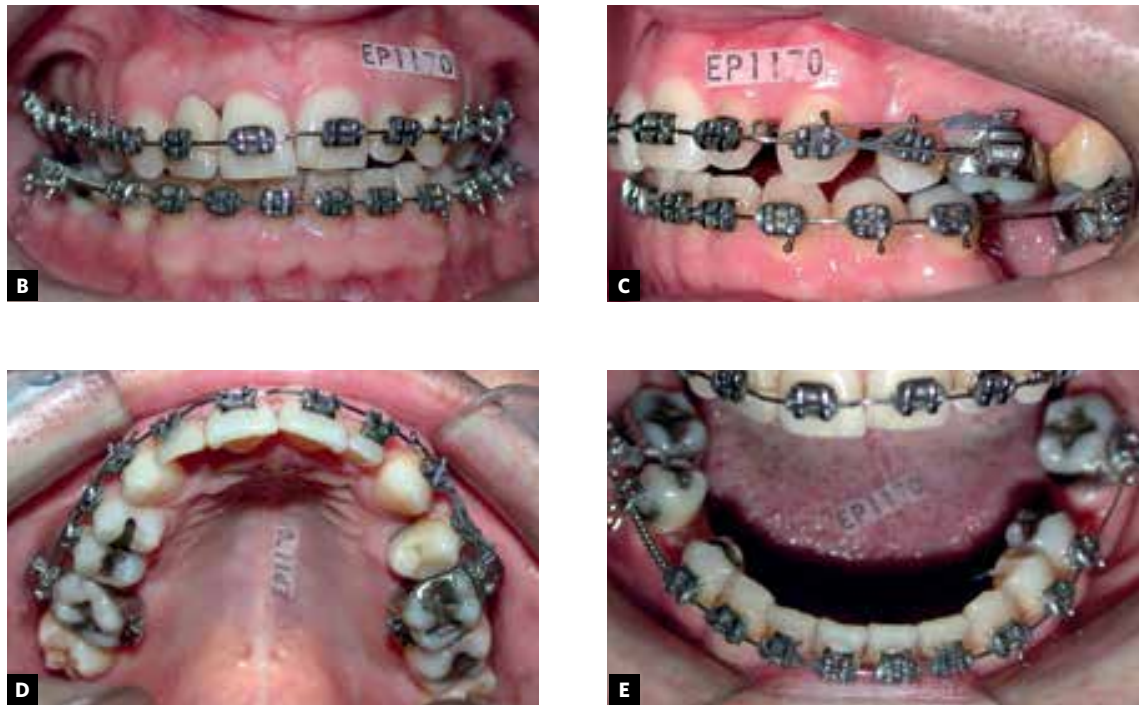

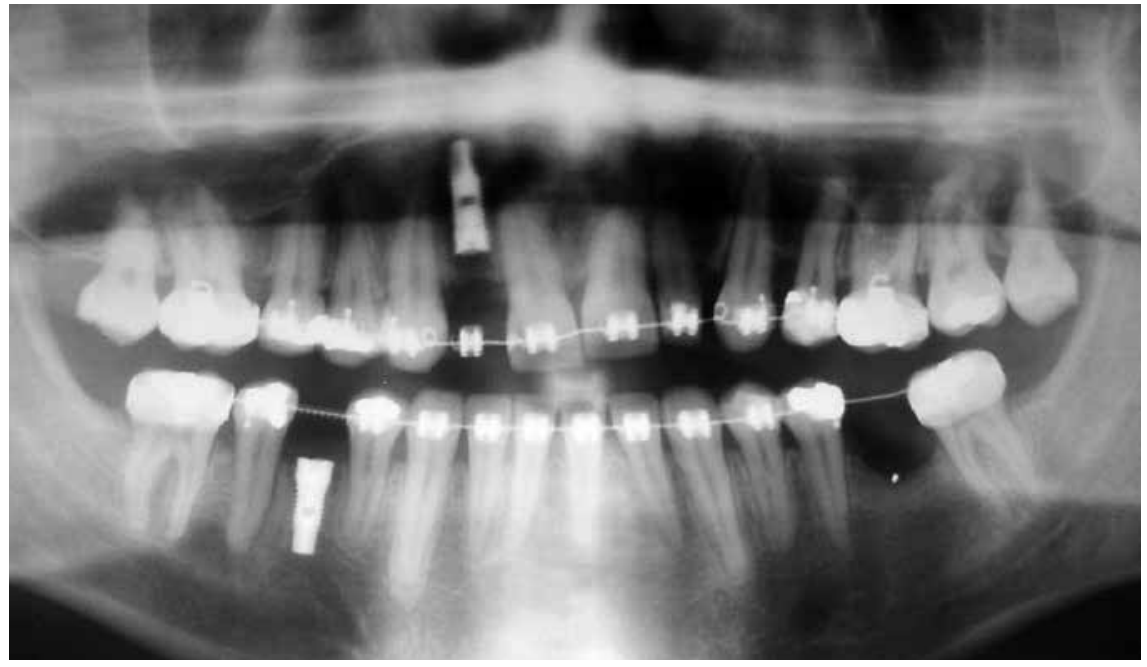

Figure 15 - Final panoramic radiograph.

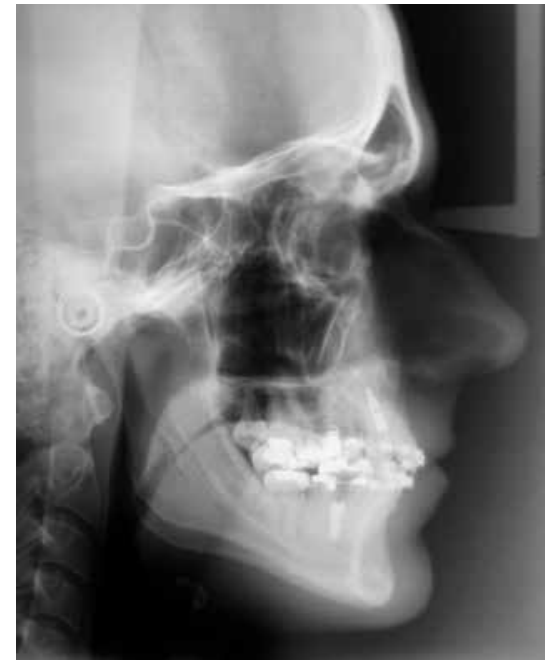

Figure 16 - Final lateral cephalogram. the brackets and tied with ligature. The remaining archwire contained in the midline bend surpasses the molar tube and the teeth receiving the active archwire receive force in buccal direction. In the present case, this movement was occasionally potentiated by the presence of an open coil between teeth \#13 and 11 .

With creation of a gradually greater space between teeth \#11 and 13, when possible, a pontic tooth was placed to simulate the maxillary right lateral incisor and improve the smile esthetics. Providing this to adult patients is very important to enhance the self-esteem and enthusiasm about the treatment (Fig 13).

Finishing bends were performed and the patient was referred for the implants, which were placed at the region of tooth \#12 and between the teeth \#44 and 45 at 15 months of treatment. At the region of the tooth \#36, the patient decided to postpone the implant placement. The mandibular appliance was removed at 19 months after treatment onset and a fixed $3 \times 3$ retainer was placed with extension to teeth \#45 and 47 (Figs 17 and 18).

In the follow-up one year after removal of the appliance, the positive aspect is achieved by the presence of a definitive crown on the implant replacing tooth \#12 (Fig 20). Though early, it seems possible to admit a reasonable stability. The patient is fully satisfied with the treatment outcome, which adequately met his chief complaint, namely to improve the quality of smile (Fig 21). 

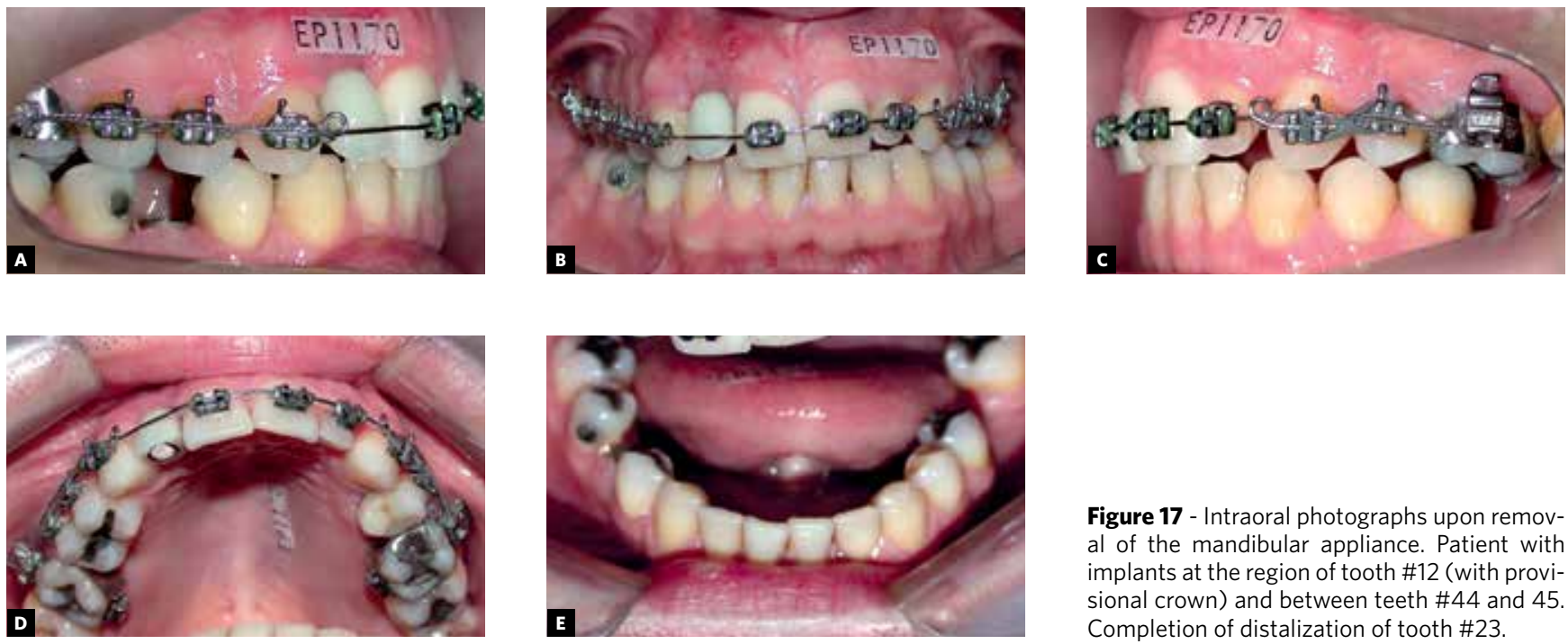

Figure 17 - Intraoral photographs upon removal of the mandibular appliance. Patient with implants at the region of tooth $\# 12$ (with provisional crown) and between teeth \#44 and 45. Completion of distalization of tooth \#23.
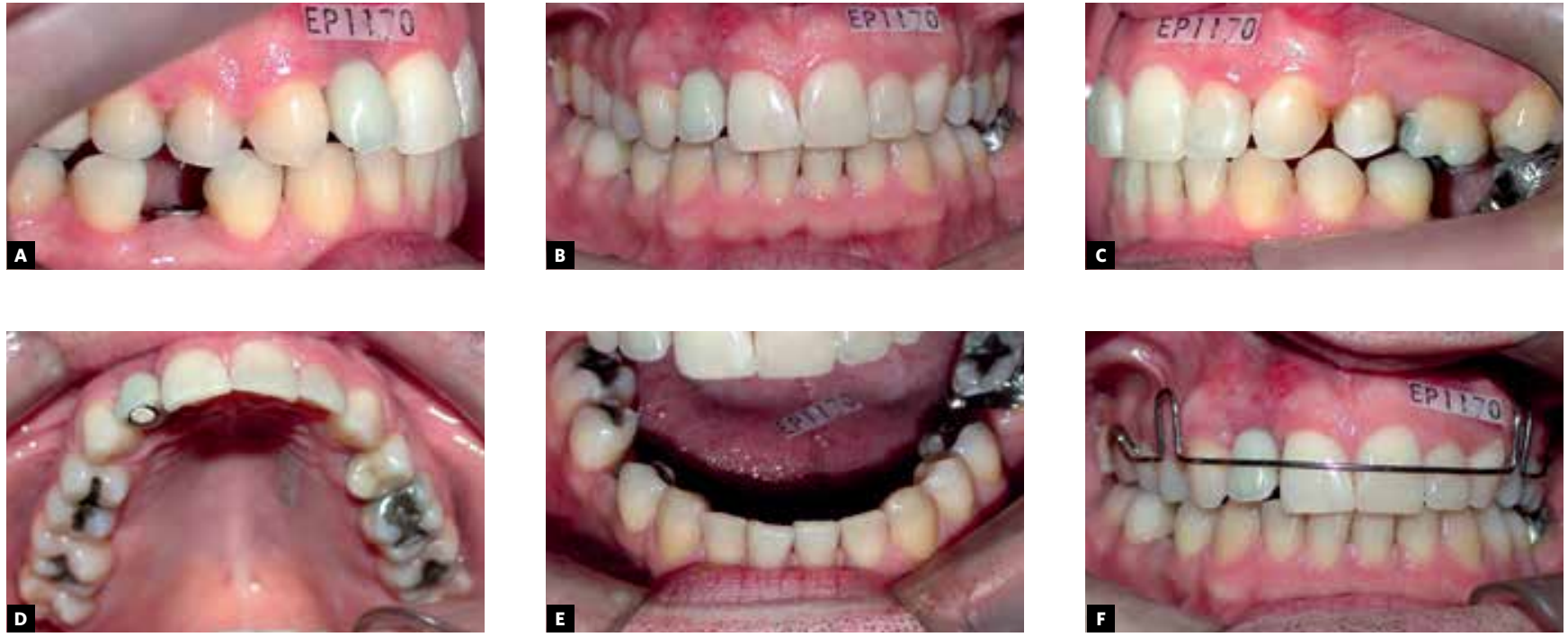

Figure 18 - Intraoral photographs after removal of maxillary appliance and esthetic restoration of teeth \#21 and 22 . The patient still has a provisional crown on the implant at the region of the maxillary right lateral incisor that is esthetically deviating. The maxillary appliance was removed at 20 months after treatment onset.
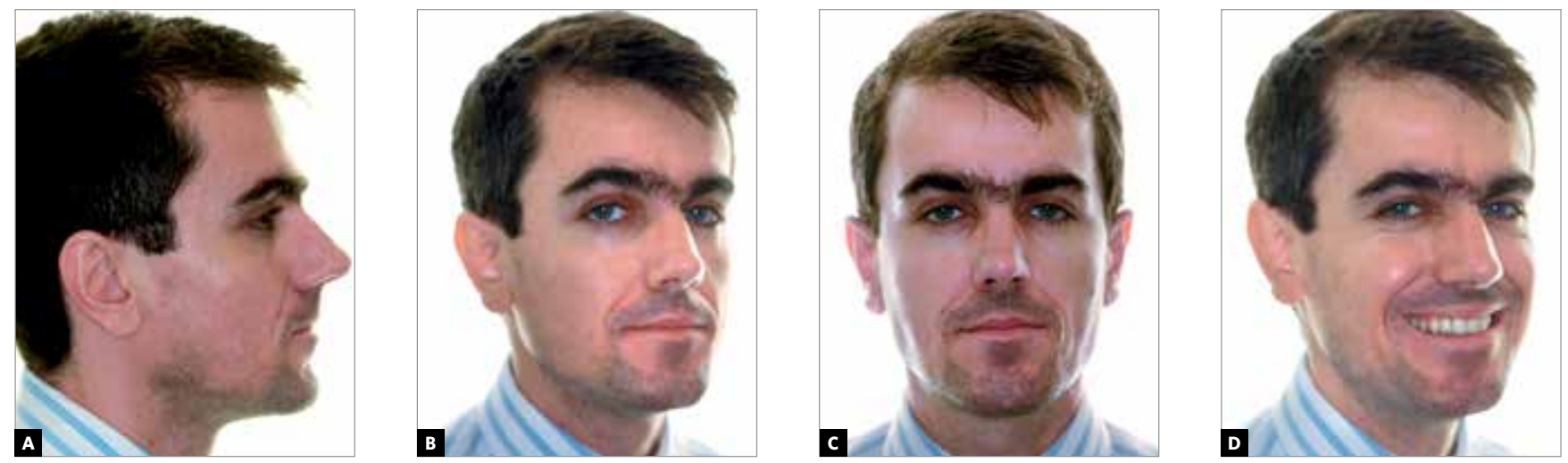

Figure 19 - Extraoral photographs after esthetic finalization of treatment, with definitive crown on the implant replacing tooth \#12. 
Figure 20 - Arch shape after one year of treatment, with night use of Hawley plate and maintenance of $3 / 3$ retainer with distal extension up to the mandibular left second molar, maintaining space for the implant that was not yet placed.
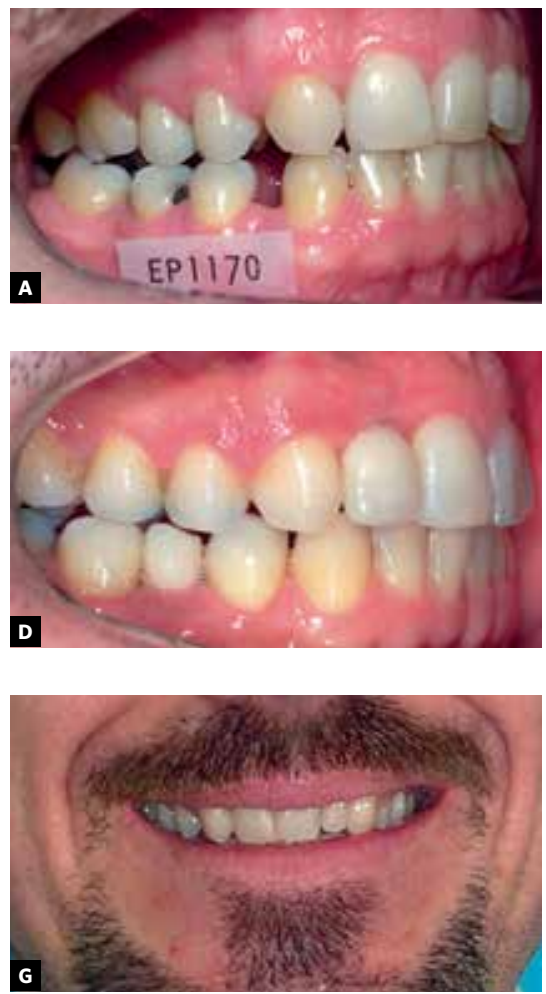
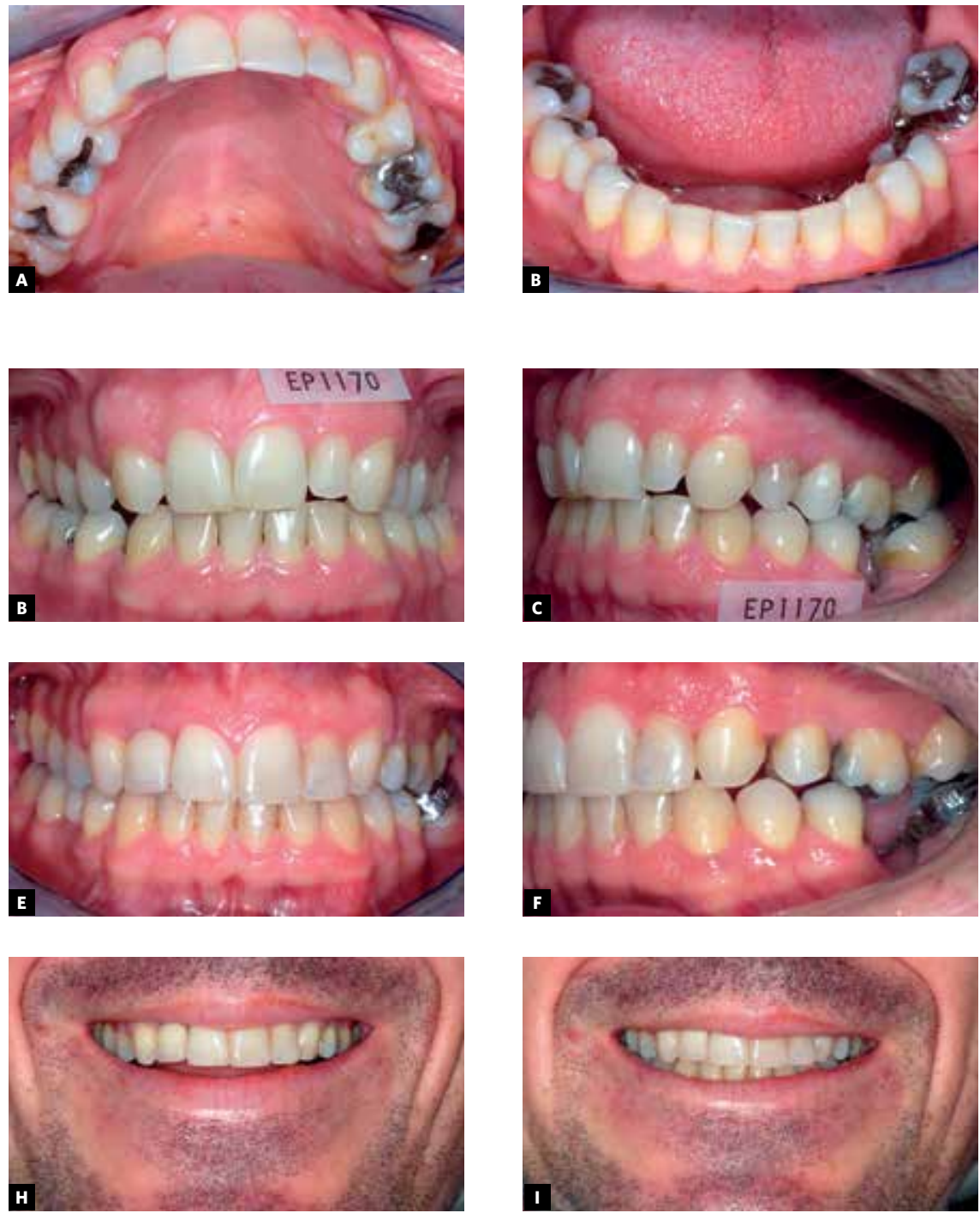

Figure 21 - Comparative intraoral photographs at treatment onset and 1-year post-treatment follow-up, evidencing the positive effects on the smile, which was the patient's chief complaint.

\section{CONCLUSION}

The orthodontic treatment in adult patients is an increasingly frequent reality. A directed and effective treatment approach is necessary to meet the expectations of these patients, which are usually related to the search for enhanced esthetics, reduced treatment time and minimum discomfort during utilization of orthodontic appliances.

The present case report demonstrated a consistent mechanics, guided by enhanced objectives, which are essential and may be achieved rapidly, providing esthetic quality of smile and potential occlusal stability to the patient.

\section{REFERENCES}

1. Andrews LF. The Six keys to normal occlusion. J Orthod. 1992 Sept;62(3):296-309.

2. Braga AS, Capelozza LF, Cavassan AO, Ozawa TO. Tratamento Ortodôntico em Adultos: uma abordagem direcionada. Rev Dent Press Ortodon Ortop Facial. 2001 Set-Out;6(5):63-80.

3. Capelozza Filho L. Diagnóstico em Ortodontia. Maringá: Dental Press; 2004.

4. Capelozza Filho L, Silva Filho OG, Ozawa TO, Cavassan AO. Individualização de braquetes na técnica straight-wire: revisão de conceitos e sugestões de indicações para uso. Rev Dent Press Ortodon Ortop Facial. 1999 Jul-Ago;4(4):87-106

5. Capelozza Filho L, Capelozza JAZ. DIAO: Diagrama individual anatômico objetivo. Uma proposta para escolha da forma dos arcos na técnica de Straight-Wire, baseada na individualidade anatômica e nos objetivos de tratamento. Rev Dent Press Ortodon Ortop Facial. 2004 Out-Nov;3(5):1-9.

6. Kokich VG. Entrevista. Rev Dent Press Ortodon Ortop Facial. 2006 NovDez;11(6):19-23.

7. Proffit WR. Contemporary orthodontics. St. Louis (MO): CV. Mosby; 1993

8. Proffit WR, Fields HW Jr, Moray LJ. Prevalence of malocclusion and orthodontic treatment need in the United States: Estimates from the NHANES III survey. Int Adult Orthodon Orthognath Surg. 1998;13(2):97-106.

9. Spear FM, Kokich VG, Mathews DP. Interdisciplinary management of anterior dental esthetics. J Am Dent Assoc. 2006 Feb;137(2):160-9. 